\title{
SIMULATION OF FATIGUE CRACK GROWTH IN INTEGRALLY STIFFENED PANELS UNDER THE CONSTANT AMPLITUDE AND SPECTRUM LOADING
}

\author{
Petr Augustin \\ Brno University of Technology, Brno, Czech Republic
}

\begin{abstract}
The paper describes methodology of numerical simulation of fatigue crack growth and its application on integrally stiffened panels made of 2024-T351 aluminium alloy using high speed cutting technique. Presented approach for crack growth simulation starts by the calculation of stress intensity factor function from finite element results obtained using MSC.Patran/Nastran. Subsequent crack growth analysis is done in NASGRO and uses description of crack growth rates either by the Forman-Newman-de Koning relationship or by the table lookup form. Three crack growth models were applied for spectrum loading: non-interaction, Willenborg and Strip Yield model. Relatively large experimental program comprising both the constant amplitude and spectrum tests on integral panels and CCT specimens was undertaken at the Institute of Aerospace Engineering laboratory in order to acquire crack growth rate data and enable verification of simulations. First analyses and verification tests of panels were performed under the constant amplitude loading. For predictions of crack growth using the spectrum loading a load sequence representing service loading of the transport airplane wing was prepared. Applied load spectrum was measured on B737 airplane within the joint FAA/NASA collection program. The load sequence is composed of 10 flight types with different severity analogous to the standardized load sequence TWIST. Before application on the stiffened panels a calculation of crack growth under the spectrum loading was performed for simple CCT specimen geometry. The paper finally presents comparison of simulations of fatigue crack propagation in two-stringer stiffened panel under the spectrum loading with verification test carried out in the IAE lab. The work was performed within the scope of the 6th Framework Programme project DaToN - Innovative Fatigue and Damage Tolerance Methods for the Application of New Structural Concepts.
\end{abstract}

\section{INTRODUCTION}

This paper presents results of activities done at the Institute of Aerospace Engineering (IAE) during its participation on the 6th Framework Programme project DaToN - Innovative Fatigue and Damage Tolerance Methods for the Application of New Structural Concepts led by Technical University Braunschweig. Full title of this project indicates that it is focused on the development of damage tolerance assessment tools for structures manufactured using newly developed methods. Selected advanced production techniques under investigation are High Speed Cutting (HSC). Laser Beam Welding and Friction Stir Welding. Their application in the aerospace industry leads to the reduction of manufacturing costs up to $30 \%$ and production time benefits. Structures manufactured using these techniques are typical by their integral character. It leads to the fact that they contain less number of fatigue and corrosion critical locations. However their comparison with differentially stiffened designs from the damage tolerance point of view is less optimistic. They lack in some cases the crack-arresting capability that is typical of riveted structures as far as crack propagation and residual strength is concerned. Example of such a behavior can be, for instance, found in [1]. 


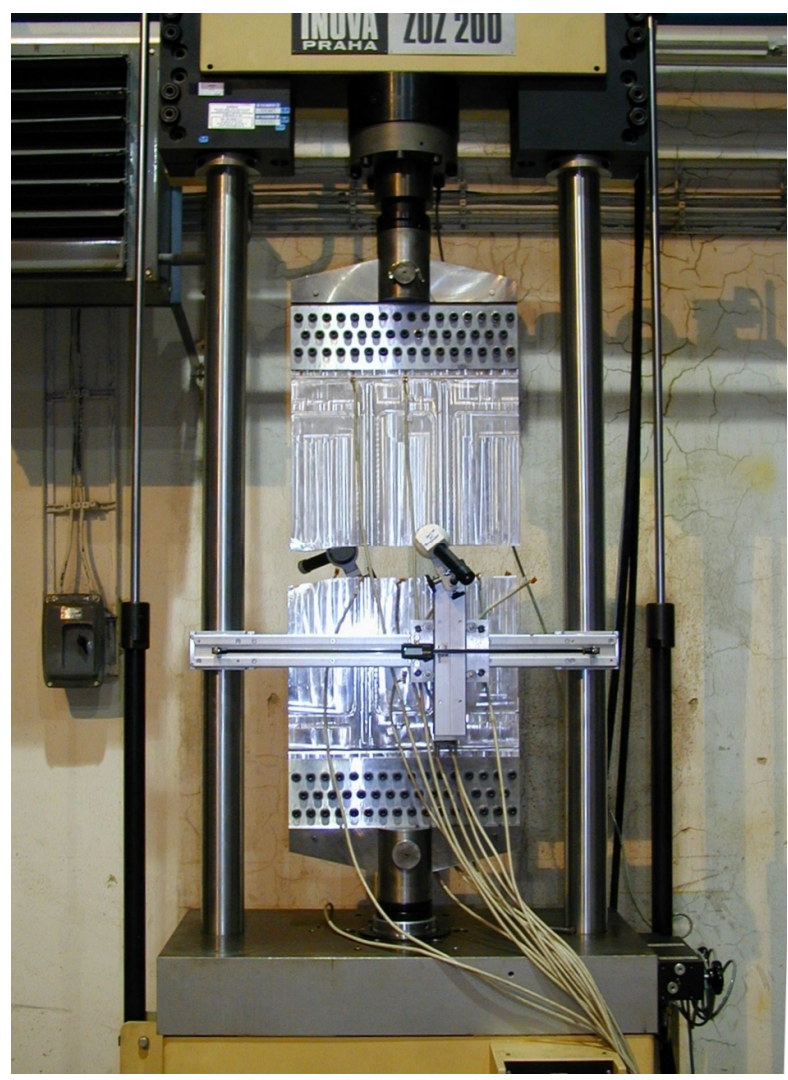

Fig. 1 - Two-stringer HSC panel at IAE laboratory

The project consists of workpackages aimed to both the developing of computational models and experimental activities. The common test program was focused on collection of experimental data mainly using the DaToN two-stringer panels shown in Figure 1. Validation of models was performed by means of a procedure during that all partners analyzed the same structure with own tool and obtained theoretical predictions were subsequently compared with results of the tests. This paper describes approach used at the Institute of Aerospace Engineering for prediction of crack growth in $450 \mathrm{~mm}$ wide two-stringer integrally stiffened panels made of 2024-T351 aluminium alloy using HSC technique.

\section{METHODOLOGY OF CRACK GROWTH ANALYSIS}

The approach starts with the calculation of stress intensity factor functions from results of finite element analysis. Simulation of crack propagation in the panel requires determination of K values for large number of crack configurations and that is why simple FE models comprising the shell elements were built. It is acceptable time consuming even when there is need of application of geometrical nonlinear solution.

Stress intensity factor is calculated from the strain energy release rate determined using the crack closure technique [2]. The method is based on the assumption that the energy $\Delta E$ released during the extension of the crack from the length $a$ to $a+\Delta a$ is identical to the energy required to close the crack (see Fig. 2). For a crack modelled with two-dimensional four nodded elements the work required to close the crack along one element side can be calculated as

$$
\Delta E=\frac{1}{2}\left[X_{1 l} \cdot \Delta u_{2 l}+Z_{1 l} \cdot \Delta w_{2 l}\right]
$$


where $X_{1 l}$ and $Z_{1 l}$ are the shear and opening forces at the crack tip node and $\Delta u_{2 l}$ and $\Delta w_{2 l}$ are the differences in shear and opening nodal displacements at the same point. The method requires two finite element analyses to calculate the energy. In the first one the forces $X_{1 l}$ and $Z_{1 l}$ are determined using the model with the crack closed. In the second step the crack is extended to the length $a+\Delta a$ which enables determination of displacements $\Delta u_{2 l}$ and $\Delta w_{2 l}$. The strain energy release rate $G$ can be calculated using the energy expressed above as
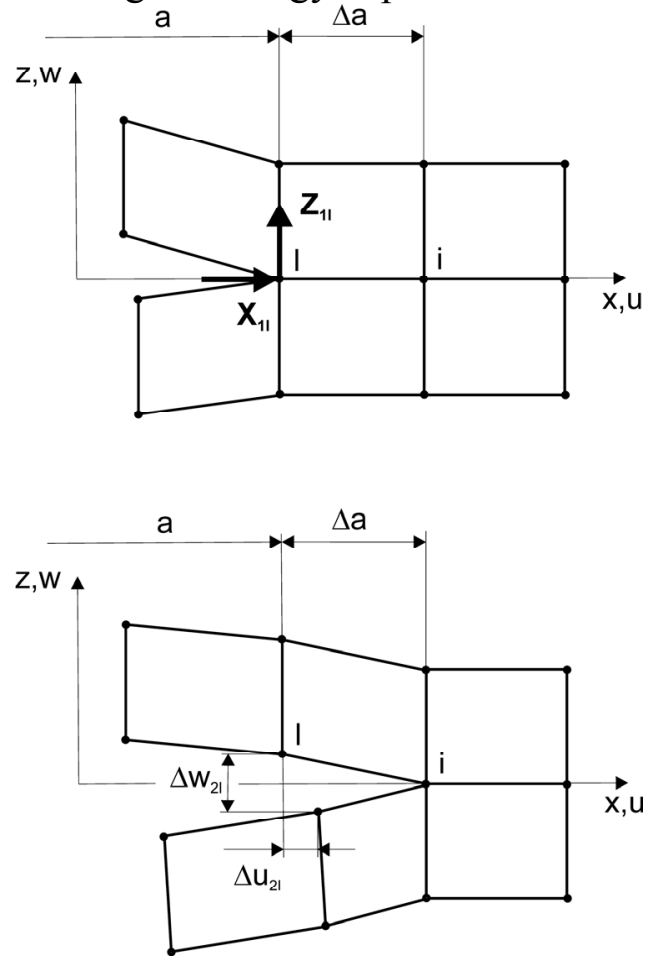

Fig. 2

$$
G=\frac{\Delta E}{\Delta A}=\frac{\Delta E}{\Delta a \cdot b}
$$

where $\Delta A$ is newly created crack surface and $b$ the width of the elements. The mode I and II components $G_{I}$ and $G_{I I}$ can be separated from the overall strain energy release rate as follows

$$
\begin{gathered}
G_{I}=-\frac{1}{2 \Delta a \cdot b} Z_{1 l} \cdot \Delta w_{2 l} \\
G_{I I}=-\frac{1}{2 \Delta a \cdot b} X_{1 l} \cdot \Delta u_{2 l}
\end{gathered}
$$

Depending on the mesh density the crack closure technique was able to calculate stress intensity factor values with the error of about $2 \%$. There is no limitation in the number of cracks in the structure and no modifications of MSC.Nastran input file are required as in the case of special crack elements.

Crack propagation evaluation was based on crack growth rate data obtained from the tests of $100 \mathrm{~mm}$ wide and $2 \mathrm{~mm}$ thick CCT specimens shown in Fig. 3. These specimens were manufactured directly from the DaToN panels after their testing. The data from the tests of CCT specimens performed at stress ratios $\mathrm{R}$ of $0.1,0.5$ and 0.8 were subsequently expressed using four 
different approaches. Two of them were based on the NASGRO equation [3] which is FormanNewman-de Konig relationship between crack growth rate $d a / d N$ and stress intensity factor range $\Delta K$

$$
\frac{d a}{d N}=C\left[\left(\frac{1-f}{1-R}\right) \Delta K\right]^{n} \frac{\left(1-\frac{\Delta K_{t h}}{\Delta K}\right)^{p}}{\left(1-\frac{K_{\max }}{K_{C}}\right)^{q}}
$$

where $\Delta K_{t h}$ is the threshold stress intensity factor range and $K_{C}$ the the critical stress intensity factor. The crack opening function $f$ for plasticity-induced crack closure is defined as

$$
f=\frac{K_{o p}}{K_{\max }}=\left\{\begin{array}{cc}
\max \left(R, A_{0}+A_{1} R+A_{2} R^{2}+A_{3} R^{3}\right), & R \geq 0 \\
A_{0}+A_{1} R, & -2 \leq R<0
\end{array}\right.
$$

where $K_{o p}$ is stress intensity factor value above which the crack is open. The coefficients are expressed as

$$
\begin{gathered}
A_{0}=\left(0,825-0,34 \alpha+0,05 \alpha^{2}\right)\left[\cos \left(\frac{\pi}{2} \frac{\sigma_{\max }}{\sigma_{0}}\right)\right]^{\frac{1}{\alpha}} \\
A_{1}=(0,415-0,071 \alpha) \frac{\sigma_{\max }}{\sigma_{0}} \\
A_{2}=1-A_{0}-A_{1}-A_{3} \\
A_{3}=2 A_{0}+A_{1}-1
\end{gathered}
$$

where $\alpha$ is a constraint factor and $\sigma_{\max } / \sigma_{0}$ is the ratio of the maximum applied stress to the flow stress. Curve fit of crack growth rate data for $\mathrm{R}=0.1,0.5$ and 0.8 using the NASGRO equation is shown in Fig. 4. It is rough approximation because of NASGRO equation isn't able to describe the 2024-T351 data typical by sigmoidal shape with several transitions in slope. Nevertheless this curve fit was used for predictions of crack growth under the spectrum loading using the Willenborg model since there is no alternative in NASGRO. Second approach was applied for simulations of crack growth in the panels under the constant amplitude loading. Thanks to the fact that calculations start at higher stress intensity factor ranges in this case it was possible to use only linear part of the data. Correspondent curve fits based on NASGRO equation are depicted in Fig. 5. The third approach shown in Fig. 6 uses the table lookup input in NASGRO. Polynomial curve fitting was applied to generate the points into the table. This approach was used for predictions under the constant amplitude and non-interaction spectrum loading. The last method is required for calculation of crack propagation using the Strip Yield model. In this model crack growth rates have to be expressed as a function of effective stress intensity factor range $\Delta K_{\text {eff }}$ instead of $\Delta K$. 


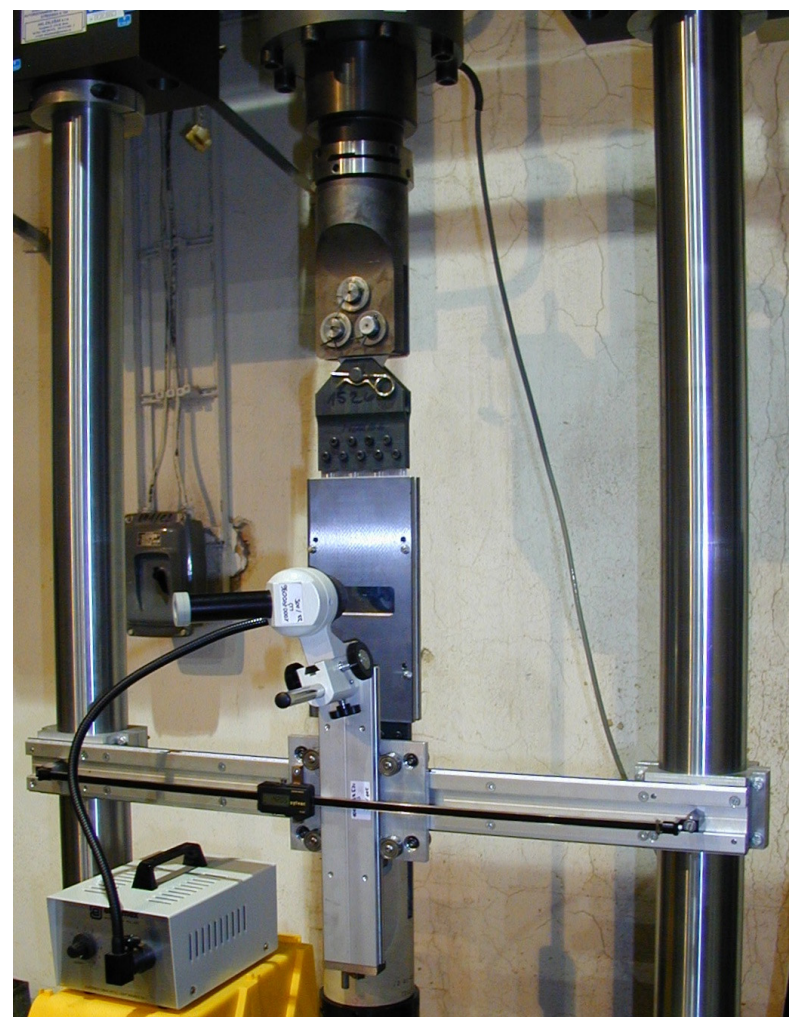

\section{Fig. 3 - CCT specimen with antibuckling restraints used for constant amplitude and spectrum tests}

Hence the effective stress intensity factor range was calculated using crack opening function (6) as

$$
\Delta K_{\text {eff }}=\frac{1-f}{1-R} \Delta K
$$

Experimental data for three different stress ratios than collapsed into single band as can be seen in Fig. 7. Again a polynom was used to fit the data and fill in the table in NASGRO.

A typical feature of integrally stiffened panels is that after the crack in the skin reaches the stiffener we have to consider parallel propagation of two cracks. One of the possibilities how to treat this problem is the use of two-dimensional growth option in NASGRO. Practically it was necessary to calculate stress intensity factors for more or less arbitrary chosen combinations of lengths of cracks in both the skin and stiffener as an input into the NASGRO. Resulting combinations of sizes of skin and stiffener cracks and corresponding $\mathrm{K}$ values are than determined during the cycle-by-cycle computational procedure by means of interpolation routine.

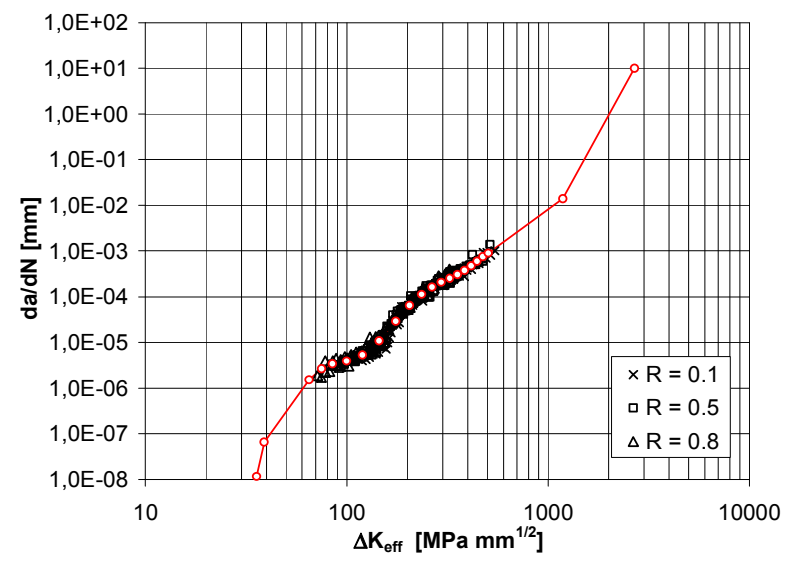

Fig. 4 - Crack growth rate data and curve fit based on the NASGRO equation 


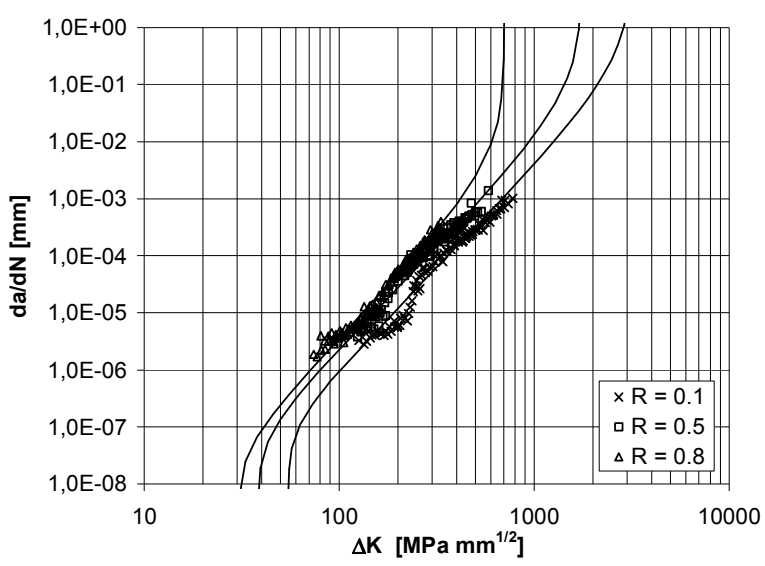

Fig. 5 - Curve fits of linear parts of data using the NASGRO equation

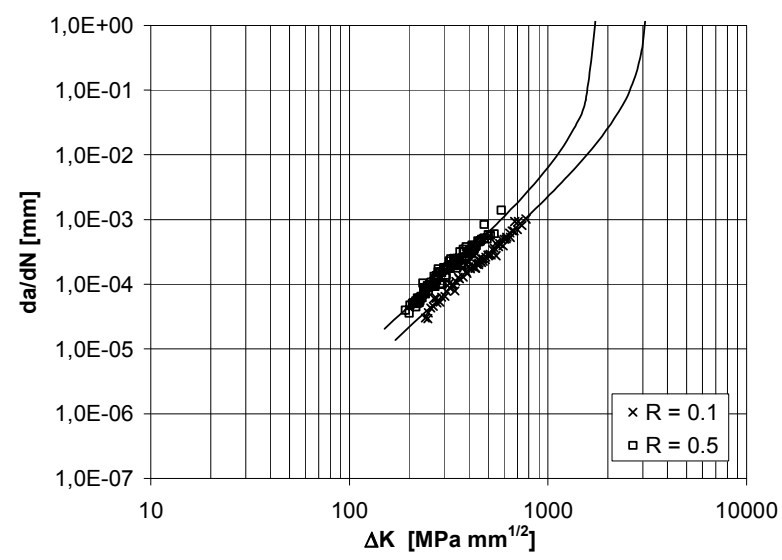

Fig. 6 - Polynomial curve fit of crack growth rate data

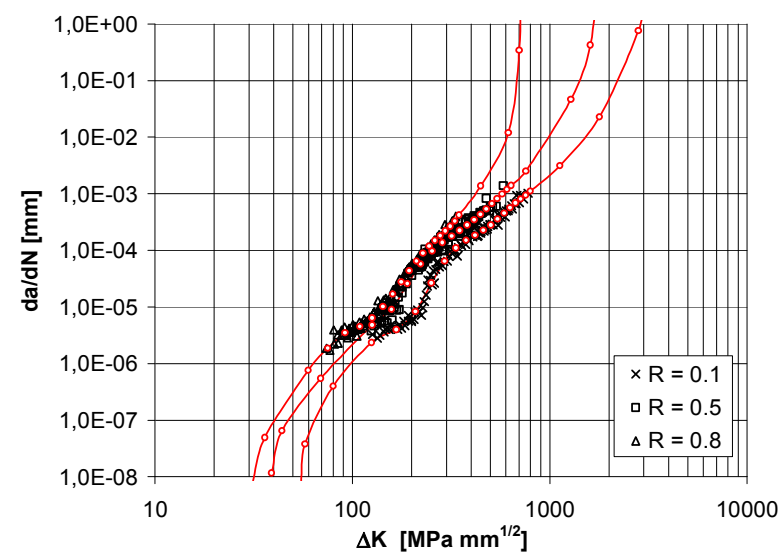

Fig. 7 - Effective stress intensity factor range against crack growth rate and polynomial curve fit

\section{THE DATON PANEL UNDER THE CONSTANT AMPLITUDE LOADING}

First analyses and verification tests of the DaToN HSC panels were performed under the constant amplitude loading at maximum nominal stress of $80 \mathrm{MPa}$ with stress ratio $\mathrm{R}=0.1$ and at maximum nominal stress of $110 \mathrm{MPa}$ with $\mathrm{R}=0.5$ respectively [4]. The fatigue cracks in the skin started from the central saw cut of $2 \mathrm{a}=20 \mathrm{~mm}$. FE model of the panel is shown in Figures 8 and 9. Load with magnitude equal to the maximum load applied during the test was uniformly distributed 
in the gripping area of the panel. The testing was done without any antibending device able to restrict the displacements perpendicular to the panel plane. From the modeling point of view it is necessary to involve the bending effects acting in the experiments. This is why the application of geometrical nonlinear solution was investigated.

Stress intensity factor functions for cracks in the skin and stiffener obtained from FE results are depicted in Figures 10 and 11. It can be seen that skin crack stress intensity factor functions show significant reduction during the growth through the stiffener. A comparison of stress intensities based on linear and nonlinear FEM analyses is also presented.

Crack propagation evaluation was based on curve fits of 2024-T351 crack growth rate data in Figures 5 and 6. Predictions of crack propagation depicted in Figures $12-15$ are in good accordance with the tests on panels. It is obvious that the best results correspond to stress intensity factor functions obtained from geometrical nonlinear analysis. The reason is in slightly smaller K values for crack approaching the stiffeners. No significant differences in predictions based on curve fits of liner part of data using NASGRO equation and on the table lookup form were found.

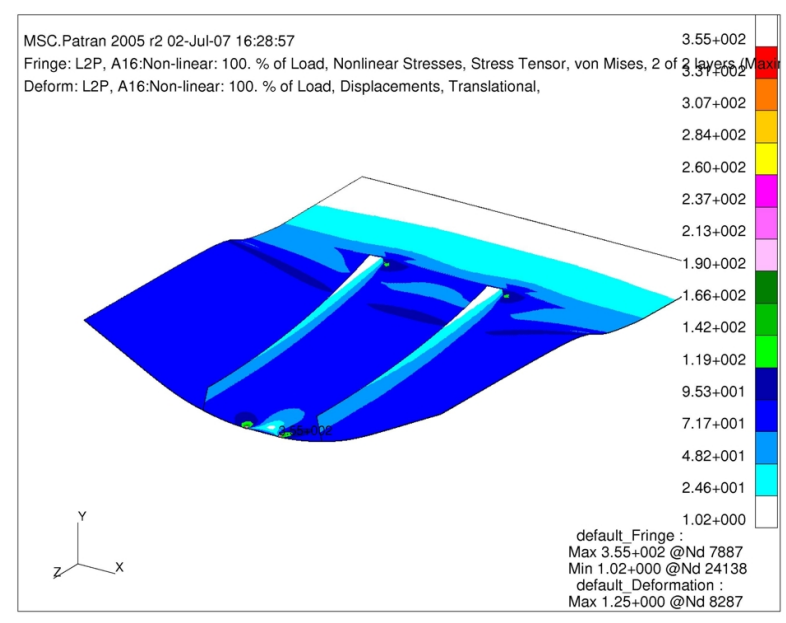

Fig. 8 - Stress contour plot for panel with central crack in the skin

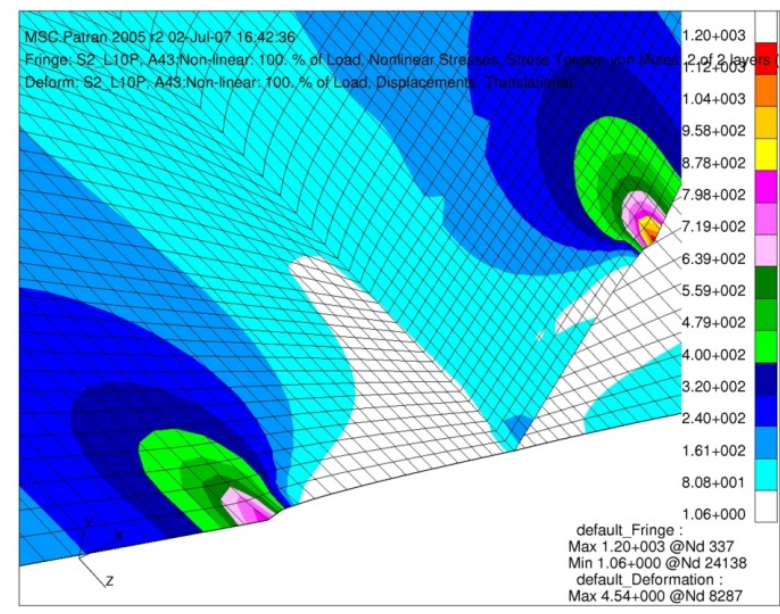

Fig. 9 - Stress field - both the skin and stiffeners are partially broken 


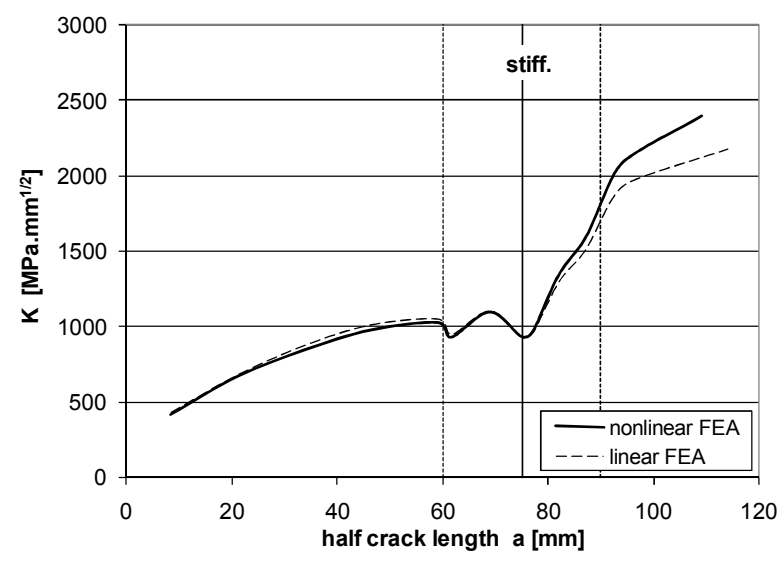

Fig. 10 - Stress intensity factor function for skin crack in the two-stringer panel

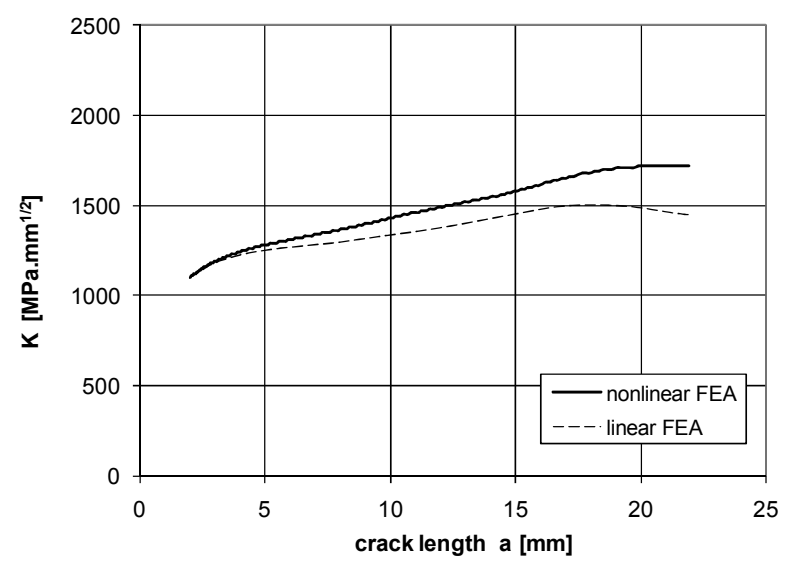

Fig. 11 - Stress intensity factor function for crack in the stiffener

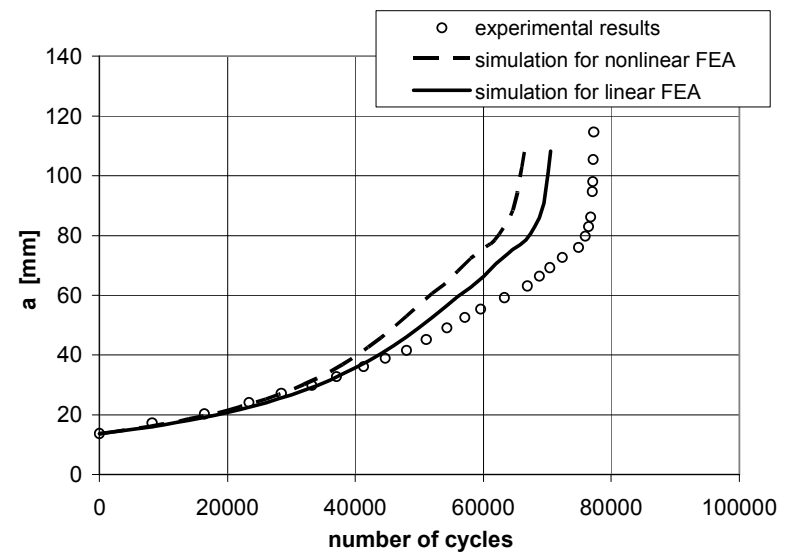

Fig. 12 - Prediction of crack growth in the skin of the two-stringer panel using NASGRO equation versus results of the test $-\sigma_{\max }=80 \mathrm{MPa}, R=0.1$ 


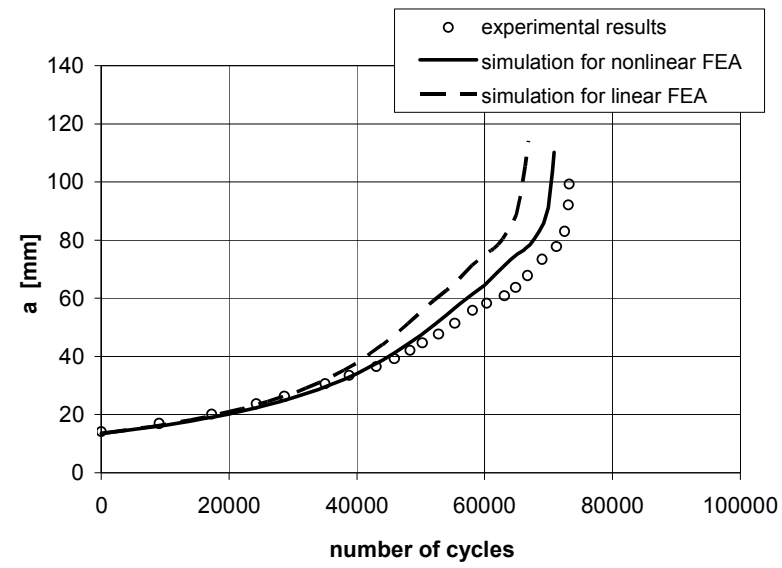

Fig. 13 - Prediction of crack growth in the skin of the two-stringer panel using NASGRO equation versus results of the test $-\sigma_{\max }=110 \mathrm{MPa}, \mathrm{R}=0.5$

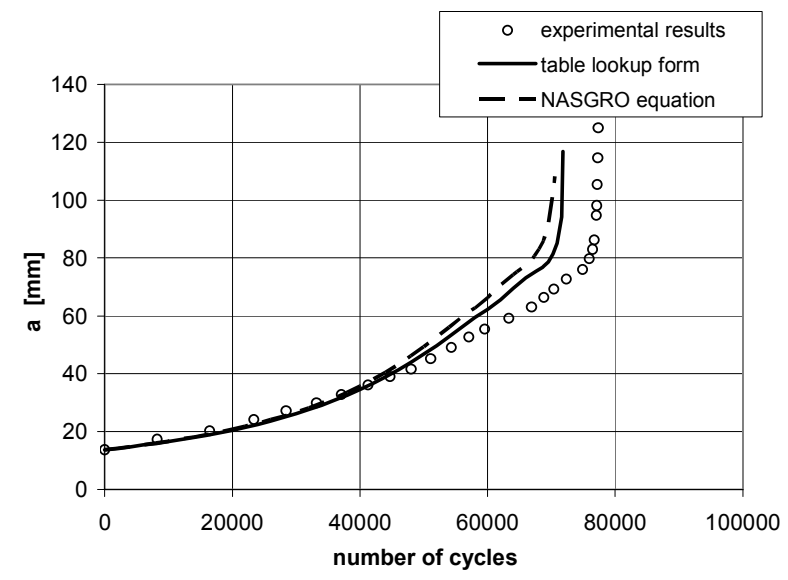

Fig. 14 - Predicted crack growth in the skin of the two-stringer panel versus results of the test (nonlin. FEA) - $\sigma_{\max }=80 \mathrm{MPa}, R=0.1$

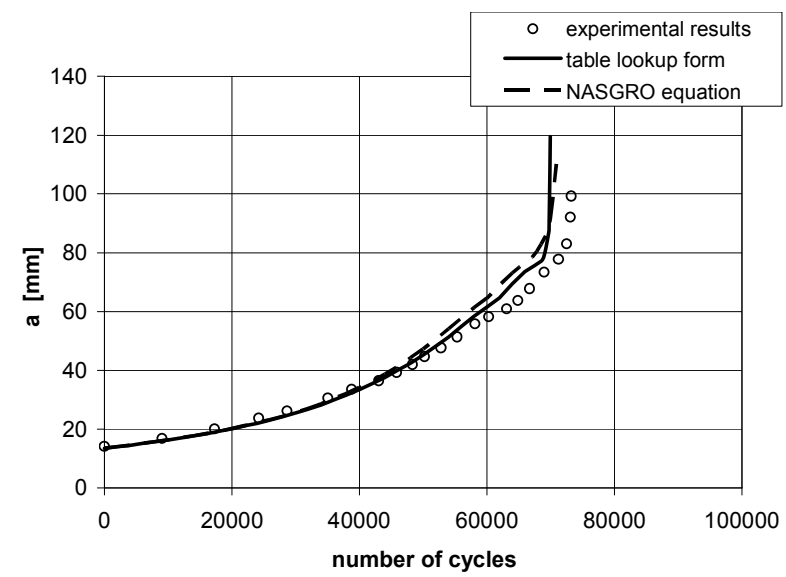

Fig. 15 - Predicted crack growth in the skin of the two-stringer panel versus results of the test (nonlin. FEA) - $\sigma_{\max }=110 \mathrm{MPa}, R=0.5$ 


\section{THE DATON PANEL UNDER THE SPECTRUM LOADING}

For predictions of crack growth and experimental verifications using the spectrum loading a load sequence representing service loading of the transport airplane wing was prepared. Up to the present relatively large amount of information concerning load spectra measured on transport aircraft has been published. Following data sources were considered in order to select the flight load spectrum for the tests:

- Large database ONERA taken from reference [5] pertaining to 1781548 flight hours flown by different aircraft operated by British Airways.

- Database ACMS (Aircraft Condition Monitoring System) kept at NLR [5]. The data were measured during 121893 flight hours representing 24358 flights of Boeing B747 aircraft.

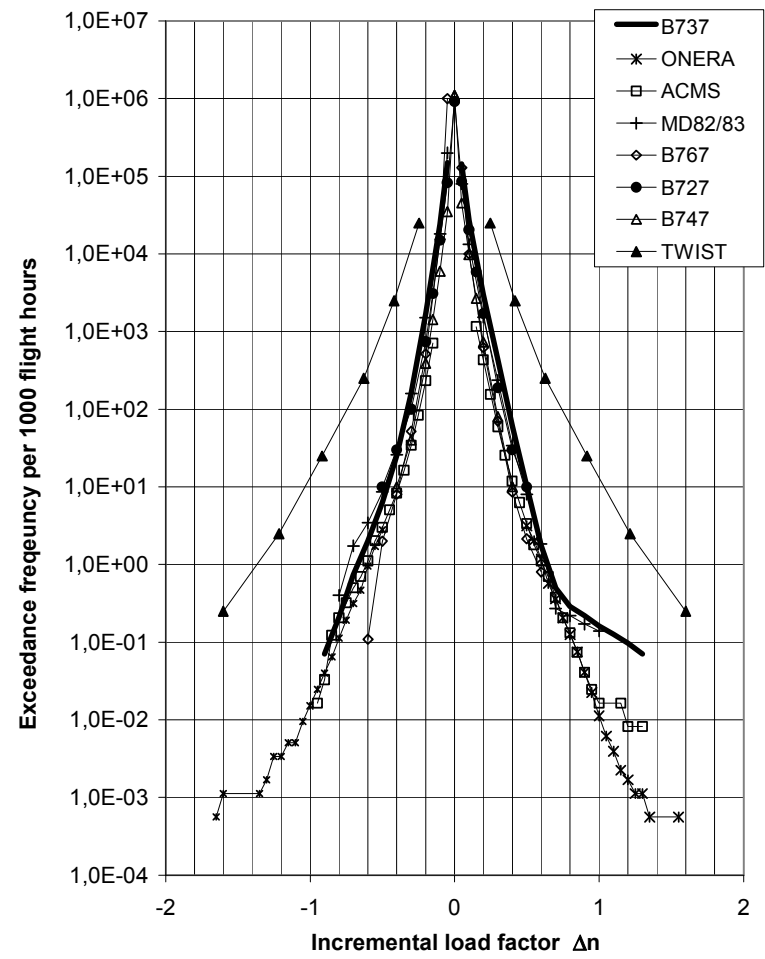

Fig. 16 - Flight load spectra of transport airplanes (TWIST exceedances per 1000 flights)
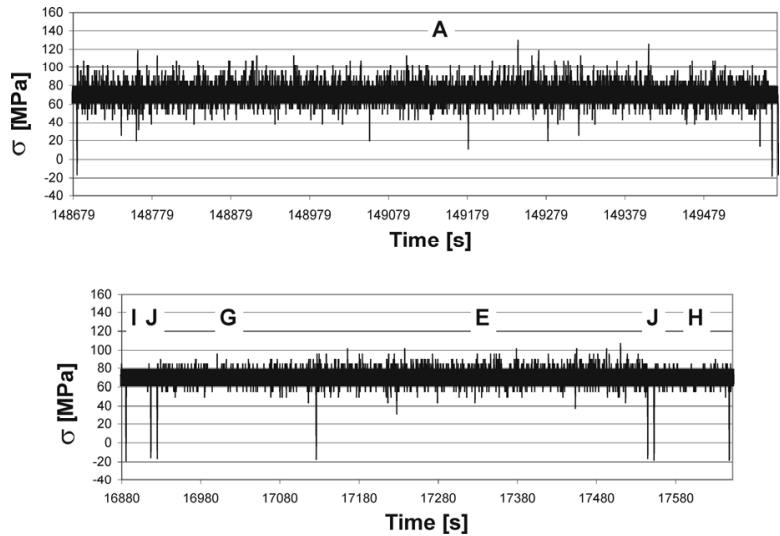

Fig. 17 - Examples of different flight types 


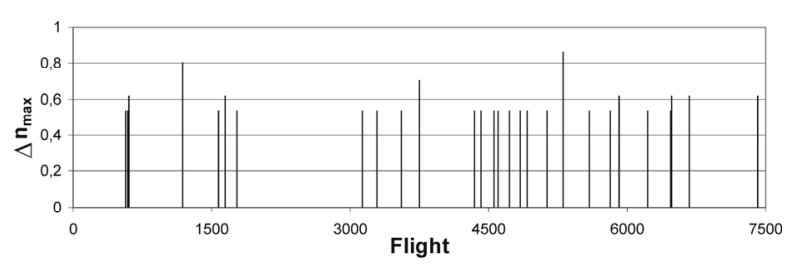

Fig. 18 - Position of the most severe flights in the sequence and magnitudes of largest load factors

- Measurements on 17 Boeing 737-400 aircraft in the extent of 19105 flight hours carried out by FAA within the Airborne Data Monitoring Systems Research Project [6].

- MD82/83 data related to the same FAA project obtained from 7120 flight hours [7].

- The dataset published by FAA collected during 9164 flight hours of the Boeing 767200ER aircraft operation [8].

- Results of the NASA VGH Program. The data were obtained using the Digital Flight Recorder System of Boeing B727 aircraft during 1765 flight hours [9].

- NASA VGH data of Boeing B747 aircraft collected during 1689 flight hours [10].

- Spectrum of the standardized load sequence of transport aircraft wing structures TWIST [11].

Figure 14 provides comparison of flight load spectra considered. It can be seen that all data with exception of the TWIST spectrum are very similar. Substantial differences lie in the omission level applied during the extraction from acquired records and in the truncation of high loads related to the extent of the database. In case of the ONERA spectrum only peaks and valleys larger then $|\Delta n|>0.5$ were recorded. It is obvious that an essential extrapolation in the area of small loads would be necessary. On the other hand the data published in references $8-10$ don't include the area of largest load factors. This is the reason for selection of measurement performed on Boeing B737 airplane (reference [6]).

An important question of the development of a load sequence is the definition of the number of flights in the repetitive block defining the magnitude of the highest load included. In accordance with many sources (for instance refs [11], [12]) the number of flights was established as one tenth of the anticipated lifetime. B 737 design service objective of 75000 flights was obtained from [13]. It leads to the repetitive block of 7500 flights. Another decision that has to be made is the omission of small loads. The spectrum of flight loads normalized to 7500 flights was trimmed on the level pertaining to cumulative frequency of 315000 . Provided that the typical magnitude of $1 \mathrm{~g}$ nominal flight stress is $70 \mathrm{MPa}$, the omission stress range is $12.46 \mathrm{MPa}$. This is a conservative choice in comparison with the recommendations in references [12] and [14].

Continuous flight load spectrum was divided in ten discrete levels and subsequently distributed into different flight types with various severities. The technique of the definition of flight types in the case of gust dominated spectra of a transport aircraft described in reference [11] was adopted in this work. The main principle based on the analysis of an influence of different weather conditions on the gust load spectrum is that the spectra of different flight types should have similar shape and the extreme value distribution of highest loads in flight types should approximate lognormal distribution. Consistently with the TWIST load sequence the number of flight types is the same as the number of load levels. Thus all flight types denoted by letters from A to J can differ in terms of the magnitude of highest load level as is shown in Fig. 17.

The load sequence is created on a flight by flight basis and the sequence of loads and flights is random. Generation of the load history is realized by the in-house computer program. All flights are closed by insertion of one compression load. The appropriate load factor is the largest load factor selected from number of peaks pertaining to one flight randomly generated from the ground load spectrum. 
Three crack growth models were applied for spectrum loading: non-interaction, Willenborg and Strip Yield model. Simple non-interaction model is fully based on crack growth rates determined from constant amplitude tests. It isn't able to reflect any retardation effects due to the load history hence conservative predictions can be expected.

Generalized Willenborg model deals with the crack growth retardation by implementation of the effective stress ratio

$$
R_{\text {eff }}=\frac{K_{\min }-K_{R}}{K_{\max }-K_{R}}
$$

that is used instead of the stress ratio for the current applied cycle of loading $R=K_{\min } / K_{\max }$. Modified residual stress intensity

$$
K_{R}=\varphi K_{R}^{W}
$$

is defined using the Willenborg residual stress intensity factor

$$
K_{R}^{W}=K_{\max }^{O L}\left(1-\frac{\Delta a}{Z_{O L}}\right)^{\frac{1}{2}}-K_{\max }
$$

where $K_{\max }^{O L}$ is the maximum stress intensity factor for the overload cycle, $\Delta a$ stands for the crack growth between the overload cycle and the current cycle and $Z_{O L}$ is the size of the overload plastic zone. The factor $\varphi$ is defined as follows:

$$
\varphi=\frac{1-\frac{\Delta K_{t h}}{K_{\max }-K_{\min }}}{\left(R_{S O}-1\right)}
$$

where $\Delta K_{t h}$ is the threshold stress intensity factor range and $R_{S O}$ is the shut-off value of the stress ratio $K_{\max }^{O L} / K_{\max }$. When this value is exceeded, the crack growth is arrested.

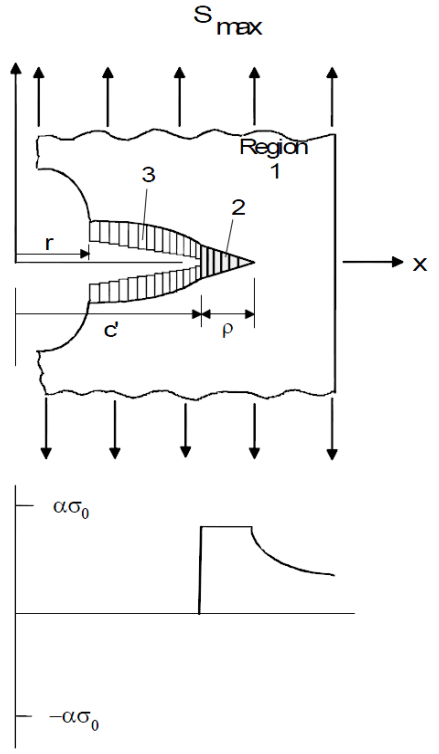

(a) Maximumstress
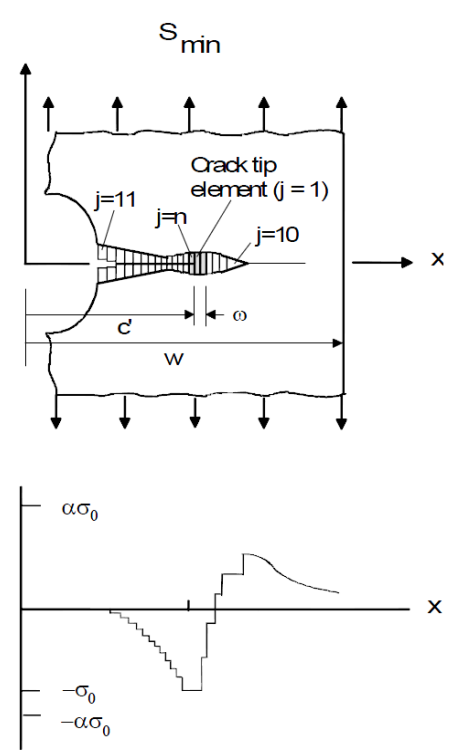

(b) Mnimumstress 
Fig. 19 - The Strip Yield model [3]

The Strip Yield model in NASGRO is based on Dugdale strip-yield model modified to leave plasticity in the crack wake. The model consists of predominantly linear elastic body with thin strip located along the crack line that contains all plastic deformation. The material in the strip is divided into the rigid-perfectly plastic bar elements (see Fig. 19). At the maximum stress the plastic elements ahead of the crack tip carry the stress $\alpha \sigma_{0}$ where the constraint factor $\alpha$ accounts for the effect of stress state on tensile yielding. At minimum stress the crack face elements behind the growing crack tip are in compression. Using the contact stresses the crack opening stress intensity factor $K_{o p}$ is calculated as a function of applied stress history.

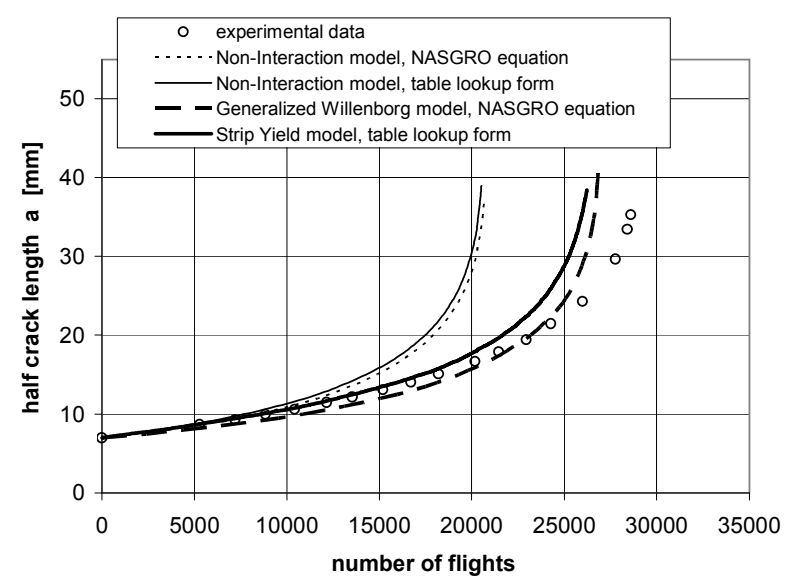

Fig. 20 - Predicted crack growth in the CCT specimen under the spectrum loading versus result of the test

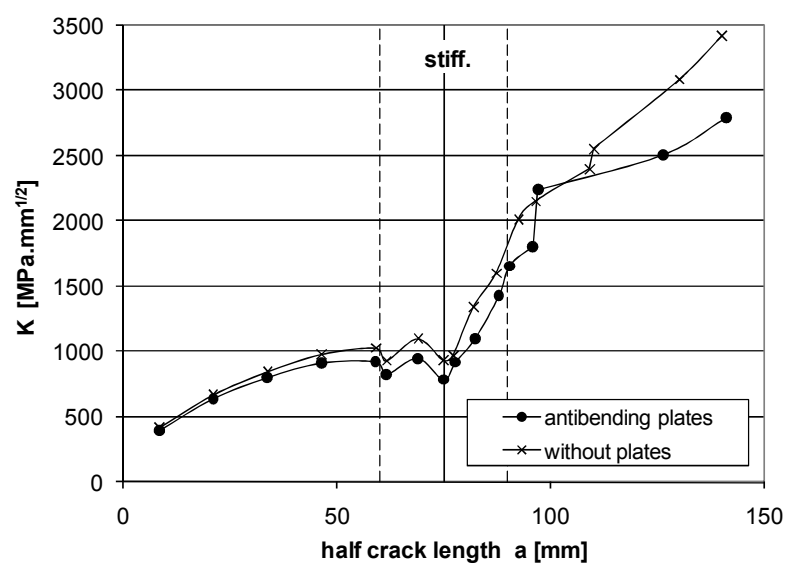

Fig. 21 - Stress intesity factor function for skin crack in the two-stringer panel with antibending plates 


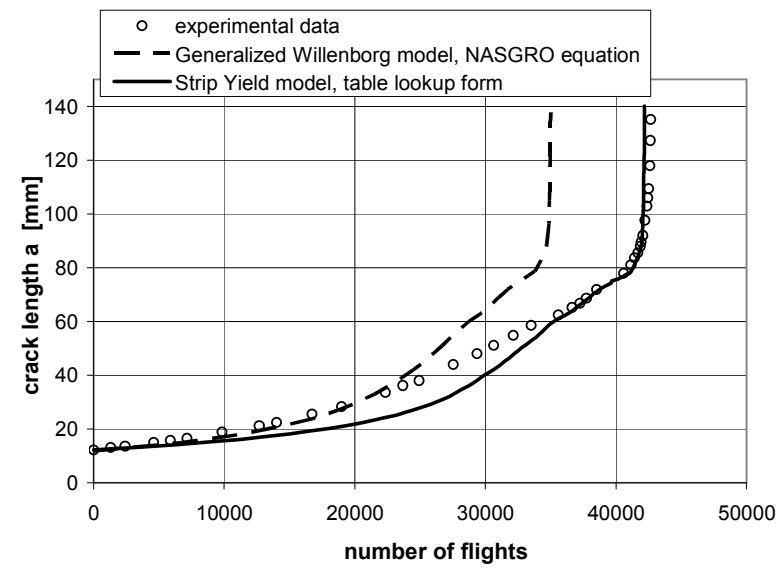

Fig. 22 - Predictions of crack growth in the skin of the two-stringer HSC panel under the spectrum loading in comparison with the test

Before application on the DaToN panel calculations of crack growth under the spectrum loading were performed for simple CCT specimen geometry. Since analytical solution of the stress intensity factor function is in this case known, it was possible to verify the crack growth analyses done in NASGRO without the influence of inaccuracy of stress intensity factor determination based on FEA. Both the analyses and the flight simulation test used for verification were performed on $100 \mathrm{~mm}$ wide and $2 \mathrm{~mm}$ thick CCT specimens. For all models the range-pair counting technique was applied. Results of calculations are shown in Fig. 20. The best predictions were obtained with Willenborg and Strip Yield models that were able to predict the fatigue crack growth life with the error less than $9 \%$. These two interaction models were finally applied also for simulation of crack growth in the DaToN two-stringer panel. Since the load sequence includes compression loads, it was decided to perform the testing with the antibending device in order to support the cracked panel in compression. The antibending device consists of two plates placed in the central part on the panel. Stress intensity factor function for skin crack pertaining to the panel in this configuration is shown in Fig. 21. It is obvious that application of antibending device leads to the reduction of stress intensity factor values for crack in the skin. Along with it the crack growth in the stiffener accelerates. It results in earlier complete failure of the stiffeners indicated by a jump increase of the skin crack stress intensity factor. Prediction of crack propagation in the DaToN panel under the spectrum loading in comparison with the test carried out at IAE laboratory is depicted in Fig. 22. In this case the crack growth lives were predicted with maximum error of about $25 \%$.

\section{CONCLUSION}

The paper is focused on the methodology of numerical simulation of fatigue crack growth and its application on integrally stiffened structures. Results of simulations of crack propagation in two-stringer integrally stiffened panels manufactured using high speed cutting technique were presented. Constant amplitude as well as spectrum loading was considered. Relatively wide experimental program comprising the tests on panels and CCT specimens was undertaken in order to acquire the crack growth rate data and enable verification of analyses.

The work was performed within the scope of the 6th Framework Programme project DaToN Innovative Fatigue and Damage Tolerance Methods for the Application of New Structural Concepts. 


\section{REFERENCES}

[ 1] Nesterenko, G. I. (2000). In: Proceedings of the $22^{\text {nd }}$ International Council of the Aeronautical Sciences. Comparison of Damage Tolerance of Integrally Stiffened and Riveted Structures, 27 August - 1 September 2000, Harrogate, United Kingdom: ICAS.

[2] Krueger, R. (2002). The Virtual Crack Closure Technique: History, Approach and Applications. Hampton: NASA Langley Research Center. (NASA/CR-2002-211628)

[ 3 ] NASGRO Reference Manual, Version 4.2. San Antonio: NASA Johnson Space Center, Southwest Research Institute.

[ 4 ] Lanciotti, A., Lazzeri, L., \& Polese, C. (2005). Description of the Test Programme, DaToN - WD - WP 3.1 - 1.0 / DIA. Pisa: University of Pisa.

[ 5 ] Jonge, J. B. de, Hol, P. A., \& van Gelder, P. A. (1994). Reanalysis of European Flight Loads Data., DOT/FAA/CT-94/21, Atlantic City: FAA, Technical Center.

[ 6 ] Rustenberg, J., Skinn, D., \& Tipps, D. O. (1998). Statistical Loads Data for Boeing 737400 Aircraft in Commercial Operations. Washington: FAA, Office of Aviation Research. (DOT/FAA/AR-98/28)

[ 7 ] Skinn, D., Tipps, D. O., \& Rustenberg, J. (1998). Statistical Loads Data for MD-82/83 Aircraft in Commercial Operations. Washington: FAA, Office of Aviation Research. (DOT/FAA/AR-98/65)

[ 8 ] Tipps, D. O., Rustenberg, J., \& Skinn, D. (2000). Statistical Loads Data for Boeing 767200ER Aircraft in Commercial Operations. Washington: FAA, Office of Aviation Research. (DOT/FAA/AR-00/18)

[9] Crabill, N. L. (1989). The NASA Digital VGH Program - Exploration of Methods and Final Results, Volume III - B727 Data 1978-1980: 1765 Hours. Hampton: NASA CR181909.

[ 10 ] Crabill, N. L. (1989). The NASA Digital VGH Program - Exploration of Methods and Final Results, Volume IV - B747 Data 1978-1980: 1689 Hours. Hampton: NASA CR181909.

[ 11 ] de Jonge, J. B., Schütz, D., Lowak, H., \& Schijve, J. (1973). A Standardized Load Sequence for Flight Simulation Tests on Transport Aircraft Wing Structures, Amsterdam, Netherlands: National Aerospace Laboratory. (NLR TR 73029U)

[12 ] Lanciotti, A., \& Lazzeri, L. (1992). Effects of Spectrum Variations on Fatigue Crack Growth. International Journal of Fatigue, 14(5), 319-324.

[ 13 ] Akdenitz, A. (2001). The Impact of Mandated Aging Airplane Programs on Jet Transport Airplane Scheduled Structural Inspection Programs. Aircraft Engineering and Aerospace Technology, 73(1), 4-15.

[14 ] Abelkis, P. R. (1980). Effect of transport aircraft wing loads spectrum variation on crack growth. In D.F. Bryan \& J.M. Potter (Eds.). Effect of Load Spectrum Variables on Fatigue Crack Initiation and Propagation, ASTM STP 714, (pp.143-169). Philadelphia: American Society for Testing and Materials. 